\title{
ATMOSPHERIC TURBIDITY OVER TAIWAN
}

\author{
C. M. LIU and T. S. FeNG \\ Department of Atmospheric Sciences, National Taiwan University, Taipei, Taiwan, R.O.C.
}

(First received 3 May 1989 and received for publication 11 December 1989)

\begin{abstract}
The atmospheric turbidity over Taiwan is inferred from the measurements of the direct solar irradiance during the period from July 1982 to June 1987. The turbidity over urban sites, which ranges from 0.30 to 0.48 (mean value 0.39 ), is significantly higher than values observed over suburban $(0.21-0.23)$, rural $(0.16-0.18)$, and high mountain (0.09) sites. The highest turbidity is observed at Taipei where a positive correlation is found between the turbidity and the daily dustfall data. Low wind speed is usually accompanied with high turbidity. When the surface wind intercepts with mountains, the localized circulation initiated by the blocking of airflow may cause efficient accumulation of aerosols and hence the observed high turbidity. The turbidity tends to be inversely proportional to the stability of the planetary boundary layer (PBL); hence there is an increase of turbidity at most stations from early morning to noontime. A positive correlation between turbidity and r.h. $(<80 \%)$ and dew point temperature is noted; a negative correlation is found between turbidity and visibility. The annual cycle of turbidity is characterized by spring-fall maxima and winter-summer minima, which is different from the cycle of winter-minimum and summer-maximum observed in the temperate zone. The seasonal change of the synoptic weather pattern occurring around Taiwan is proposed to explain the observed annual cycle.
\end{abstract}

Key word index: Atmospheric turbidity.

\section{INTRODUCTION}

Changes of atmospheric trace species caused by anthropogenic activities may greatly affect the global and regional climate through radiation-dynamic processes (Wang et al., 1986; Ramanathan, 1988). Among species of major concern, aerosols interact with the solar and terrestrial radiative transfer, which can influence the global circulation (and hence climate) depending on their optical properties, concentration, location, and the surface albedo, solar zenith angle, cloud cover, etc. (Coakley and Cess, 1983, 1985; Potter and Cess, 1984; Reck and Hummel, 1981; Cess et al., 1985).

The atmospheric turbidity, also known as the total aerosol optical depth caused by extinction along the local vertical direction (Ångström, 1964; Liou, 1980), can be inferred from the direct solar flux measured at surface by comparing the measured data with output from an idealized clean-air model (Unsworth and Monteith, 1972). Such data can provide useful information on the increase of aerosols, and can be implemented into a regional model to study the aerosol effect.

In the past, the characteristics of turbidity were examined at many different areas. Unsworth and Monteith (1972) analyzed turbidity data in Britain based on the radiation data obtained during 1966-1970; Flowers et al. (1969) studied the turbidity over the U.S. during 1961-1966; Yamashita (1974) compared the turbidity in an urban and a rural environments in Toronto with data measured during 1956-1971; Peterson et al. (1981) used data obtained from July 1969 to July 1975 to study the turbidity over central North Carolina; Uboegbulam and Davies (1983) studied the turbidity in eastern Canada during the period from 1968 to 1978; Galindo (1986) dealt with the turbidity data measured during 1911-1980 to study the regional climatic effect of aerosols in Mexico City; Al-Jamal et al. (1987) analyzed the turbidity in Kuwait using data measured in 1985 and 1986.

In this paper, the atmospheric turbidity over Taiwan (Fig. 1) is evaluated using measurements of the direct solar irradiance during the period from July 1982 to June 1987. Moreover, the spatial and temporal variation of turbidity, and the influence of meteorological parameters are carefully examined.

\section{ESTIMATION OF TURBIDITY}

The mathematical process used to retrieve the atmospheric turbidity is similar to that used by Uboegbulam and Davies (1983) and Al-Jamal et al. (1987). According to Paltridge and Platt (1976), the direct solar irradiance measured at surface in a cloudless sky can be expressed as

$$
I=I_{\mathrm{o}}\left(T_{\mathrm{oz}} T_{\mathrm{R}}-A_{\mathrm{w}}\right) \exp \left[-\tau_{\mathrm{a}}^{*}\right],
$$

where $I$ is the beam radiation over the whole solar spectrum $\left(\mathrm{W} \mathrm{m}^{-2}\right) ; I_{\mathrm{o}}$, the corresponding extraterrestrial radiation $\left(\mathrm{W} \mathrm{m}^{-2}\right) ; T_{\mathrm{oz}}$, the ozone transmissivity; $T_{\mathrm{R}}$, the Rayleigh transmissivity; $A_{\mathrm{w}}$, the water vapor absorptivity; $\tau_{a}^{*}$, the total aerosol optical depth due to extinction along the incident beam path. By measuring $I$ and estimating $I_{\mathrm{o}}, T_{\mathrm{oz}}, T_{\mathrm{R}}$ and $A_{\mathrm{w}}, \tau_{\mathrm{a}}^{*}$ can be obtained from Equation (1), i.e.

$$
\tau_{\mathrm{a}}^{*}=-\ln \left[I / I_{\mathrm{o}}\left(T_{\mathrm{oz}} T_{\mathrm{R}}-A_{\mathrm{w}}\right)\right] .
$$




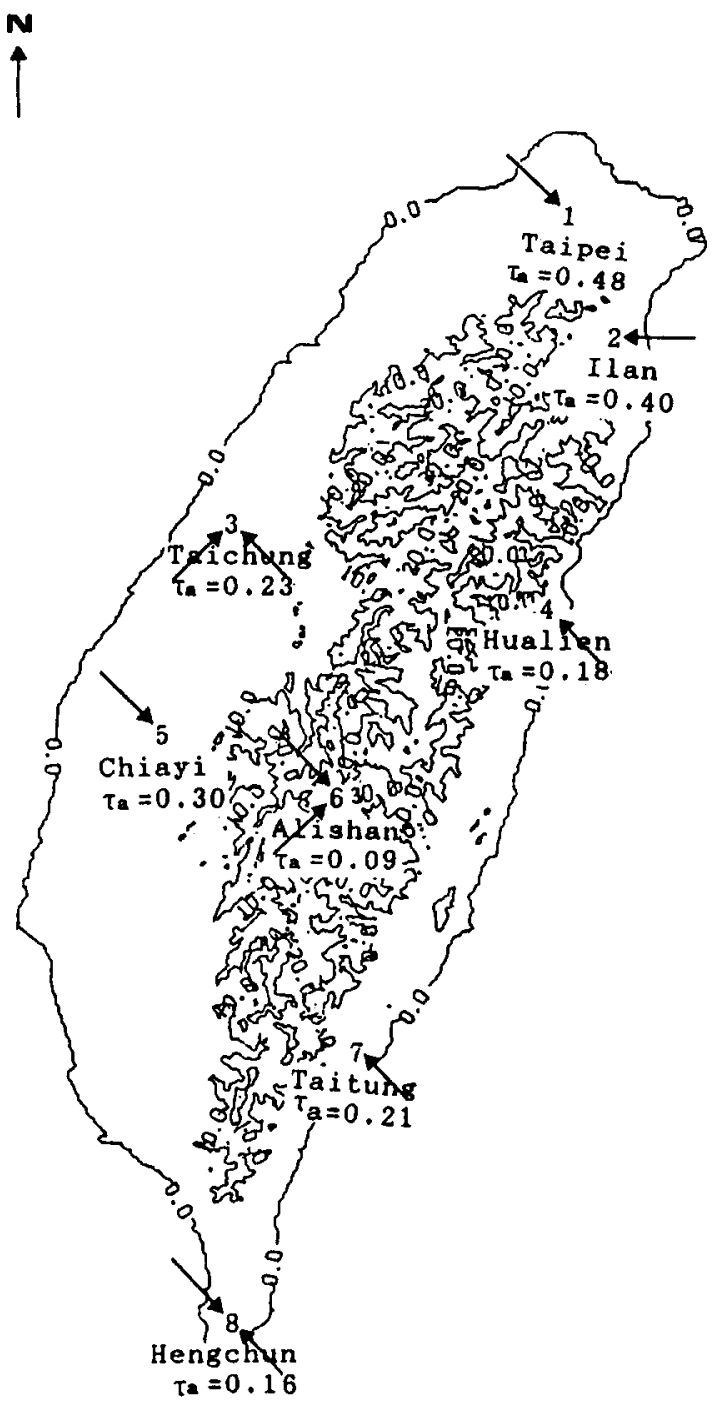

Fig. 1. The eight stations in Taiwan (refer to Table 1). The isohypse has a unit of $100 \mathrm{~m} . \tau_{\mathrm{a}}$ is the mean turbidity. The prevailing wind direction for high turbidity at each station is marked by arrow.

In a plane-parallel atmosphere, the aerosol optical path along the local vertical direction (or the turbidity) $\tau_{\mathrm{a} 1}$ can be related to $\tau_{\mathrm{a}}^{*}$ by (Liou, 1980)

$$
\tau_{\mathrm{a}}^{*}=\tau_{\mathrm{a} 1} m_{\mathrm{a} 1},
$$

where $m_{\mathrm{a} 1}$ designates the optical air mass $\left(m_{\mathrm{a} 1}=\sec \theta\right)$, and $\theta$ is the solar zenith angle which is estimated according to List (1971). Unsworth and Monteith (1972), Uboegbulam and Davies (1983) and Al-Jamal et al. (1987) have applied Equation (3) to estimate the turbidity. However, since the extinction coefficient of aerosol is a function of wavelength, the broadband optical depth $\tau_{\mathrm{a} 1}$ depends upon the optical air mass. Therefore, $\tau_{\mathrm{a} 1}$ cannot provide a unique index of aerosol extinction (Unsworth and Monteith, 1972).

Hänel (1987) proposes the following formula to correct the air mass effect, i.e.

$$
\tau_{\mathrm{a}}^{*}=m_{\mathrm{a} 2} \tau_{\mathrm{a} 2}\left[1-\alpha \beta\left(m_{\mathrm{a} 2}-1\right)^{0.5}\left(\tau_{\mathrm{a} 2}\right)^{0.25}\right] .
$$

In Equation (4), $m_{\mathrm{a} 2}$ is the relative optical path defined as the ratio of the actual and the vertical optical depth, and is parameterized as

$$
1 / m_{\mathrm{a} 2}=\cos \theta+a /\left\{(b-\theta)^{c}\left[1+d\left(z-z^{*}\right)+e\left(z-z^{*}\right)^{2}\right\},\right.
$$

where $z$ is the height of the observation site; constants $\left(a, b, c, z^{*}\right)$ are $\left(0.4938,95.40^{\circ}, 1.5114,3000 \mathrm{~m}\right)$; Constants $(d, e)$ are $\left(-5.96 \times 10^{-4} \mathrm{~m}^{-1}, 1.02 \times 10^{-7} \mathrm{~m}^{-2}\right)$ and $\left(-6.34 \times 10^{-3} \mathrm{~m}^{-1},-1.41 \times 10^{-6} \mathrm{~m}^{-2}\right)$ for a clear and a turbid atmosphere, respectively. In Equation (4)

$$
\alpha=0.1+0.035 \exp \left[-0.95 \ln \left(m_{\mathrm{a} 2} / 7.72\right)\right],
$$

while $\beta=1.09 \pm 0.15$ and $0.95 \pm 0.09$ for continental clear background and pollution aerosols, respectively.

In general, except at clean background sites, the turbidity $\tau_{\mathrm{a} 2}$ estimated from Equation (4) is close to $\tau_{\mathrm{a} 1}$ estimated from Equation (3), with a bias of 0.01-0.03 and a root-mean-square difference of $0.02-0.04$ for the data used in this paper (Table 1). The percentage difference is within $10 \%$. In the following section, $\tau_{a 2}$ will be used to analyze the characteristics of aerosol attenuation and hereafter be denoted as $\tau_{\mathbf{a}}$.

The extraterrestrial radiation $I_{\mathrm{o}}$ in Equation (2) is equal to the solar constant $S_{\mathrm{o}}\left(1367 \mathrm{~W} \mathrm{~m}^{-2}\right.$ based on Fröehlich (1987)) multiplied by the square of the ratio of the distance $(d)$ between the Earth and the Sun, and the mean distance $\left(d_{\mathrm{m}}\right)$ (List, 1971; Paltridge and Platt, 1976).

The parameter equation formulated by Fröehlich and Shaw (1980) is used to estimate the Rayleigh transmissivity $T_{\mathrm{R}}$. Hence, $T_{\mathrm{R}}=\exp \left(-\tau_{\mathrm{R}} m\right)$ with $\tau_{\mathrm{R}}$ $=0.0998$ and $m=\sec \theta$. The air mass correction for $m$ is negligible for the calculation of Rayleigh, ozone and water vapor transmissivity.

The equations proposed by Lacis and Hansen (1974) are used to calculate the ozone transmissivity $T_{\mathrm{oz}}$. Hence, $T_{\mathrm{oz}}=1-A_{\mathrm{oz}}$ with $A_{\mathrm{oz}}$, the ozone absorptivity in u.v. $\left(A_{\mathrm{oz}}^{\mathrm{uv}}\right)$ and visible $\left(A_{\mathrm{oz}}^{\mathrm{vis}}\right)$. For the u.v. region,

$$
\begin{aligned}
A_{\mathrm{oz}}^{\mathrm{uv}}(x)= & 1.082 x /(1+138.6 x)^{0.805} \\
& +0.0658 x /\left[1+(103.6 x)^{3}\right] .
\end{aligned}
$$

For the visible region,

$$
A_{\mathrm{oz}}^{\mathrm{vis}}(x)=0.02188 x /\left(1+0.042 x+0.000323 x^{2}\right),
$$

where $x=U_{\mathrm{oz}} m / 1000$, and $U_{\mathrm{oz}}$ is the total column ozone (in Dobson units). The monthly average total ozone (Fig. 2) measured by a Dobson spectrometer in Taipei (station 1, Fig. 1) during the period 1965-1982 is used in this study, with the assumption that the monthly mean total column ozone does not vary significantly across the island.

The water vapor absorptivity $A_{w}$ is estimated according to Lacis and Hansen (1974), i.e.

$$
A_{\mathrm{w}}(y)=2.9 y /\left[(1+141.5 y)^{0.635}+(5.925 y)\right],
$$

where $y=W_{\mathrm{e}} m$, and $W_{\mathrm{e}}$ is the effective water vapor amount. According to Lacis and Hansen (1974) and 
Table 1. The eight stations in Taiwan. $\tau_{a 1}$ is estimated from Equation (3), while $\tau_{\mathbf{a} 2}$ is from Equation (4)

\begin{tabular}{|c|c|c|c|c|c|c|c|c|c|}
\hline No. & Name & Latitude & Longitude & Elevation & $\begin{array}{c}\text { Total } \\
\text { no. of } \\
\text { cloudless } \\
\mathrm{h}\end{array}$ & $\begin{array}{c}\text { Mean } \\
\tau_{\mathrm{a} 1} \\
\text { (s.d.) }\end{array}$ & $\begin{array}{c}\text { Mean } \\
\tau_{\mathrm{a} 2} \\
\text { (s.d.) }\end{array}$ & $\begin{array}{c}\left(\tau_{\mathrm{a} 2}\right. \\
\text { Bias }\end{array}$ & rms \\
\hline 1 & Taipei & $25^{\circ} 02^{\prime}$ & $121^{\circ} 31^{\prime}$ & 8 & 753 & $\begin{array}{c}0.45 \\
(0.41)\end{array}$ & $\begin{array}{c}0.48 \\
(0.44)\end{array}$ & 0.029 & 0.042 \\
\hline 2 & I'an & $24^{\circ} 46^{\prime}$ & $121^{\circ} 45^{\prime}$ & 7.4 & 802 & $\begin{array}{c}0.38 \\
(0.34)\end{array}$ & $\begin{array}{c}0.40 \\
(0.36)\end{array}$ & 0.024 & 0.035 \\
\hline 3 & Taichung & $24^{\circ} 09^{\prime}$ & $121^{\circ} 41^{\prime}$ & 83.8 & 1665 & $\begin{array}{c}0.22 \\
(0.15)\end{array}$ & $\begin{array}{c}0.23 \\
(0.16)\end{array}$ & 0.015 & 0.019 \\
\hline 4 & Hualien & $23^{\circ} 58^{\prime}$ & $121^{\circ} 37^{\prime}$ & 17.6 & 920 & $\begin{array}{c}0.17 \\
(0.21)\end{array}$ & $\begin{array}{c}0.18 \\
(0.22)\end{array}$ & 0.011 & 0.018 \\
\hline 5 & Chiayi & $23^{\circ} 30^{\prime}$ & $120^{\circ} 25^{\prime}$ & 26.8 & 1912 & $\begin{array}{c}0.28 \\
(0.25)\end{array}$ & $\begin{array}{c}0.30 \\
(0.27)\end{array}$ & 0.019 & 0.029 \\
\hline 6 & Alishan & $23^{\circ} 31^{\prime}$ & $120^{\circ} 48^{\prime}$ & 2401.1 & 485 & $\begin{array}{c}0.08 \\
(0.21)\end{array}$ & $\begin{array}{c}0.09 \\
(0.23)\end{array}$ & 0.035 & 0.044 \\
\hline 7 & Taitung & $22^{\circ} 45^{\prime}$ & $121^{\circ} 09^{\prime}$ & 8.9 & 1144 & $\begin{array}{c}0.20 \\
(0.32)\end{array}$ & $\begin{array}{c}0.21 \\
(0.33)\end{array}$ & 0.012 & 0.021 \\
\hline 8 & Hengchun & $22^{\circ} 00^{\prime}$ & $120^{\circ} 45^{\prime}$ & 22.3 & 1455 & $\begin{array}{c}0.15 \\
(0.17)\end{array}$ & $\begin{array}{c}0.16 \\
(0.18)\end{array}$ & 0.013 & 0.020 \\
\hline
\end{tabular}

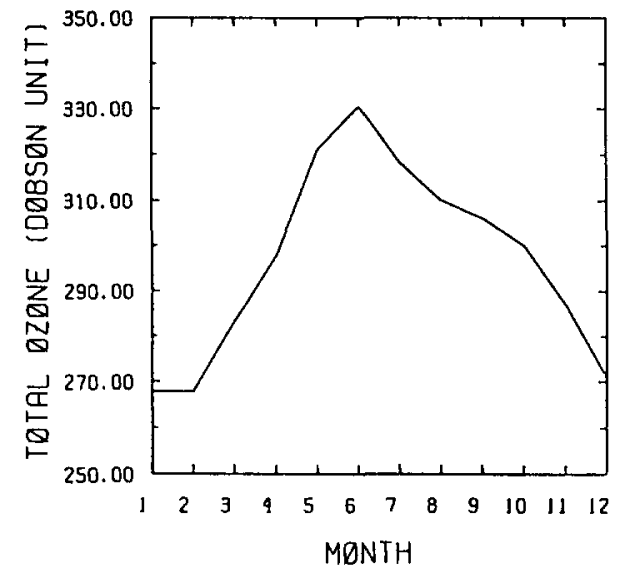

Fig. 2. The monthly mean total column ozone (Dobson Unit) in Taipei (station 1).

Al-Jamal et al. (1987),

$$
W_{\mathrm{e}}=W\left(p / p_{\mathrm{o}}\right)^{0.75}\left(t_{\mathrm{o}} / t\right)^{0.5}
$$

where $W(\mathrm{~cm})$ is the precipitable water column, $p_{\mathrm{o}}$ $=1013 \mathrm{mbar}, t_{\mathrm{o}}=273 \mathrm{~K} ; p$ and $t$ are the air pressure and temperature, respectively. The precipitable water column, $W$, is estimated by using the equation proposed by Tomasi (1977), i.e.

$$
\ln W=a+b t_{\mathrm{d}},
$$

where $t_{\mathrm{d}}$ is the dew point temperature $\left({ }^{\circ} \mathrm{C}\right.$ ) at the ground. Linear regression of the precipitable water estimated from the sounding data measured at site close to Taipei during 1982-1987 gives the coefficients $a=0.2196$ and $b=0.607$.

Uboegbulam and Davies (1983) discussed the error induced by using Equation (11) in estimating the precipitable water, and concluded that the error in $\tau_{\mathrm{a}}$ is negligible except in very clean areas. In polluted areas, errors in $\tau_{\mathrm{a}}$ are less than 0.03 . In this paper, Equation (11) introduces an error of about 0.4 (below $10 \%$ of the mean value) in estimating $\tau_{\mathrm{a}}$ at Taipei.

\section{DATA}

The radiation and meteorological data were measured at eight surface observational stations operated by the Central Weather Bureau (CWB) of the Republic of China (Fig. 1 and Table 1). Eppley pyrheliometers, model NIP, are used to measure the direct solar radiation. All the instruments were operated and calibrated regularly by CWB following the guidelines of the World Meteorological Organization. The measurements covered the period from July 1982 to June 1987. The atmospheric turbidity at each hour with $100 \%$ sunshine duration and $0-10 \%$ cloud cover is retrieved following the mathematical procedure outlined in the above section, and these results compose the dataset for analysis in the following sections.

Stations 1, 3 and 5 are located on the west coast of Taiwan island, while stations 2,4 and 7 are on the east coast. The east and west of the island are separated by the Central Mountain Range with mountains above $2 \mathrm{~km}$ height in general. Station 6 is located at the top of a high mountain with an altitude of $2406.1 \mathrm{~m}$.

\section{RESULTS AND DISCUSSIONS}

\section{Urban-rural comparison}

Table 1 lists the mean turbidity observed at every station. At urban stations (1,2 and 5), it ranges from 0.30 to 0.48 (mean value 0.39 ), whereas it ranged from 0.25 to 0.55 (mean value 0.4 ) at urban sites in England (Unsworth and Monteith, 1972). The highest turbidity of 0.48 is observed in Taipei (station 1). The standard 
Table 2. The percentage frequency of occurrence of $\tau_{\mathrm{a}}$ in different ranges at different stations

\begin{tabular}{lccccccccccc}
\hline No. & $\mathbf{0 . 0 - 0 . 1}$ & $0.1-0.2$ & $0.2-0.3$ & $0.3-0.4$ & $0.4-0.5$ & $0.5-0.6$ & $0.6-0.7$ & $0.7-0.8$ & $0.8-0.9$ & $0.9-1.0$ & $>1.0$ \\
\hline 1 & 6.7 & 22.2 & 17.1 & 10.8 & 9.4 & 7.8 & 5.4 & 4.1 & 2.7 & 1.3 & 12.5 \\
2 & 14.3 & 18.6 & 18.8 & 13.4 & 6.6 & 6.5 & 4.0 & 3.5 & 3.9 & 2.6 & 7.8 \\
3 & 18.4 & 28.7 & 23.7 & 13.8 & 8.5 & 4.1 & 1.7 & 0.7 & 0.2 & 0.1 & 0.1 \\
4 & 38.8 & 27.0 & 16.0 & 10.5 & 3.3 & 1.2 & 0.7 & 0.8 & 0.8 & 0.2 & 0.7 \\
5 & 13.0 & 24.4 & 23.4 & 17.6 & 9.3 & 4.8 & 2.5 & 1.4 & 0.7 & 0.3 & 2.6 \\
6 & 71.3 & 6.1 & 5.7 & 3.9 & 2.3 & 2.5 & 2.0 & 1.0 & 1.3 & 1.3 & 2.6 \\
7 & 51.8 & 19.1 & 8.8 & 4.8 & 3.2 & 1.8 & 1.7 & 1.3 & 1.3 & 1.5 & 4.7 \\
8 & 50.0 & 21.2 & 11.8 & 7.4 & 4.0 & 2.3 & 1.5 & 0.6 & 0.3 & 0.5 & 0.4 \\
\hline
\end{tabular}

deviation (s.d.) of turbidity at every urban station is comparable to (but smaller than) the mean value, which indicates considerable variability in the retrieved turbidity dataset. Table 2 lists the percentage frequency of occurrence of different turbidity ranges at every station. A wide range of turbidity is clearly recognizable at urban sites. The frequency of occurrence of turbidity larger than 1 is as high as $12.4 \%$ at Taipei.

During the period from 1982 to 1987 Taipei station has collected and weighed the daily dustfall $\left(\mathrm{kg} \mathrm{km}^{-2} \mathrm{day}^{-1}\right)$. Figure 3a plots the annual variation of dustfall. A large amount of falling dust is observed in spring (April and May) and fall (October), whereas a small amount of dust is observed in summer (July and August) and winter (December and February). The turbidity data at Taipei also show such seasonal variations (Fig. 3b). The correlation between the falling dust and the turbidity data in Fig. 3 is 0.702 . Hence, a positive correlation between the retrieved atmospheric turbidity and the localized falling dust is applicable at urban sites.

The mean turbidity observed at suburban stations ( 3 and 7 ) ranges from 0.21 to 0.23 (mean value 0.22 ), while at rural stations ( 4 and 8 ) it ranges from 0.16 to 0.18 (mean value 0.17 ). According to Unsworth and Monteith (1972), the mean turbidity for British rural sites ranged from 0.1 to 0.4 (mean value 0.25 ). Hengchun (station 8), located at the southern tip of Taiwan, reports a fairly low turbidity of 0.16 . The s.d. of turbidity at suburban and rural sites are in general larger than the mean value (Table 1). This fact suggests that occasionally there is high turbidity at remote areas, possibly owing to the long range transport of pollutants (Peterson et al., 1981) or localized accumulation of aerosols. In Table 2, the frequency of occurrence of turbidity at stations $3,4,7$ and 8 shows that the chance of turbidity smaller than 0.2 is higher than $50 \%$; however the turbidity can still be larger than 1 (e.g. a $4.8 \%$ frequency at station 7 ).

Alishan (station 6) at a high mountain peak has a mean turbidity of 0.09 which is very low and is close to the 0.05 value reported by Unsworth and Monteith (1972) for a northerly site in England. A large s.d. and low frequency of turbidity larger than 0.1 are seen, similar to the suburban and rural stations.

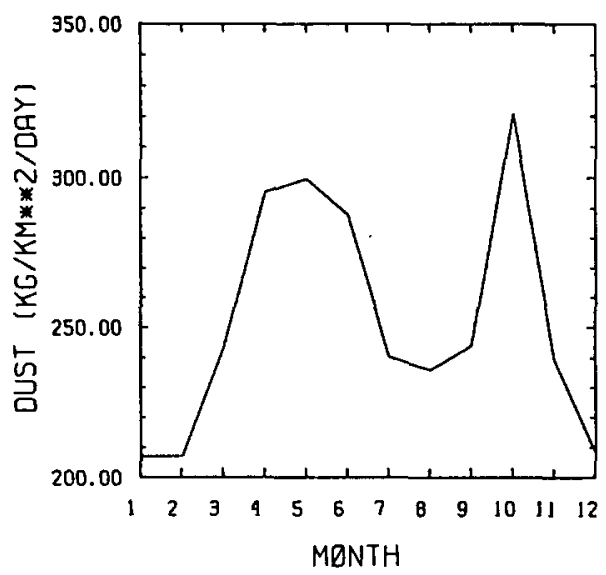

(a)

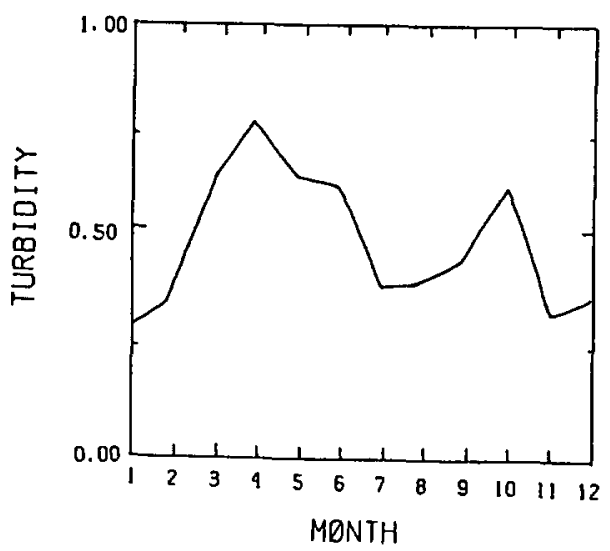

(b)

Fig. 3. The monthly variation of the (a) falling dust and (b) turbidity in Taipei (station 1).

\section{Diurnal variation}

In order to analyze the characteristics of the diurnal variation of atmospheric turbidity, mean hourly turbidities are calculated with a minimum requirement of 10 observations in each hour. In general, the temporal dispersion of the available datasets at every station is 
fairly even between 07:00 and 17:00. Figure 4a shows that at most stations the turbidity tends to increase from early morning till noontime or even till late afternoon. For instance, stations 1,2 and 8 observe the highest turbidities of $0.70,0.50$ and 0.28 at 15:00, 11:00 and 13:00, respectively. Peterson et al. (1981) have discussed the reasons behind the daytime turbidity increase, such as maximum daytime anthropogenic activity, diurnal cycle of solar radiation, and diurnal variation of mixing height and temperature. Yamashita (1974) has stated that the turbidity factor may vary even when the water vapor and dust content of the atmosphere remain constant.

In this study, through analyzing the relationship between the turbidity and the Turner stability factor (Appendix) (Fig. 4b), it is found that at almost every station the atmospheric turbidity increases with the destabilization of the boundary layer. For instance, at stations 1,2 and 8 the turbidity increases from the neutral state $\left(\tau_{\mathrm{a}}=0.40,0.24\right.$ and 0.11 , respectively) toward the extremely unstable state $\left(\tau_{\mathrm{a}}=0.50,0.50\right.$ and 0.22 , respectively). Since low surface wind speed, high solar radiation and warm temperature (i.e. high mixing layer height) are key factors for the instability of the PBL, the atmospheric turbidity tends to increase with the decrease of the zenith angle (Fig. 4c).

Figure 4 also suggests that the localized photochemical activities which generate particulate aerosols, or the horizontal transport of pollutant at different stations also play an important role on the diurnal variation of turbidity. Hence the turbidity at different stations peaks at different hours (Fig. 4a).

\section{Variation of turbidity with meteorological parameters}

Similar to the derivation of the mean hourly turbidity, the mean turbidities under the conditions of a specific range of a certain meteorological parameters are also calculated. In Figs $5 \mathrm{a}$ and $5 \mathrm{~b}$, the variation of turbidity with respect to the surface wind speed and the surface wind direction is plotted. Most stations observe high turbidity when the surface wind speed is smaller than or equal to $2 \mathrm{~ms}^{-1}$, which suggests that the turbidity inferred from the direct solar flux measurement reflects the aerosols generated and accumulated locally (Uboegbulam and Davies, 1983). However, different stations have different prevailing wind directions (Fig. 5b and Fig. 1) for the aerosol accumulation, which may be related to the synoptic weather system and the local orographic environment.

Figure 1 shows that the interception of surface wind with localized topography can efficiently cause high turbidity (or accumulation of aerosols) at stations 1, 2, $4,5,7$ and 8 , possibly through a localized circulation initiated by the blocking of airflow. Whereas, at stations 3 and 6, downstream transport of aerosols from the urban site Chiayi seems to cause the observed higher turbidity. In general, the northwesterly wind is accompanied by high turbidity at stations located in western Taiwan; while the southeasterly wind causes
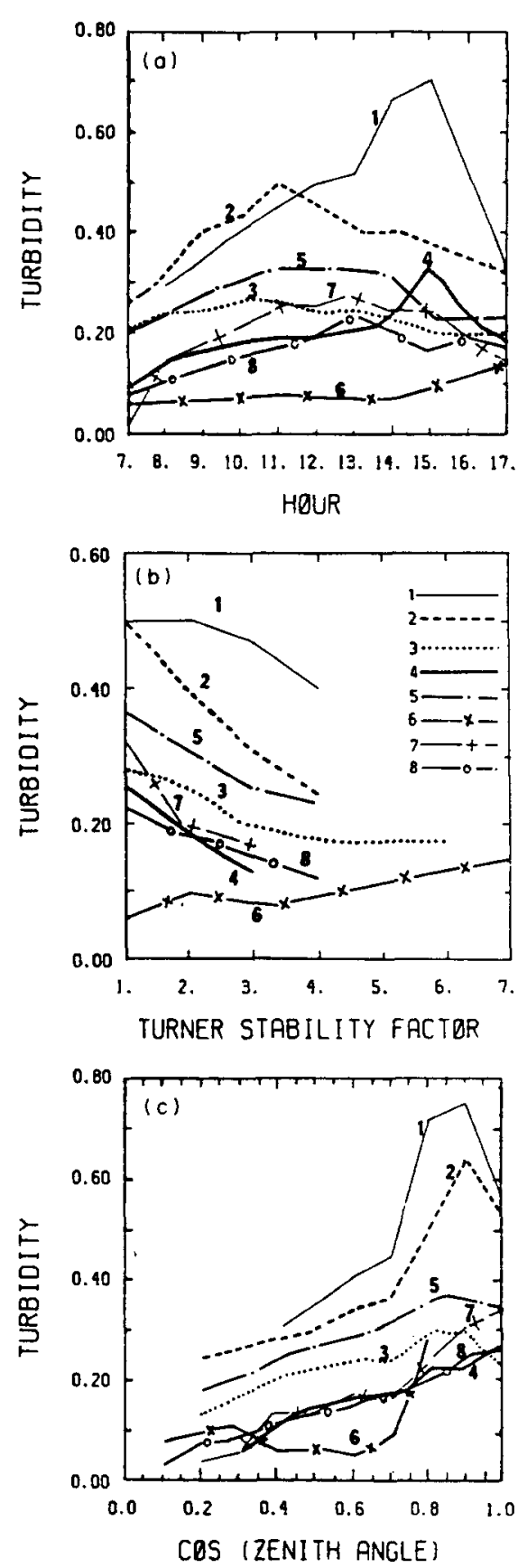

Fig. 4. The variation of mean turbidity averaged at different (a) daytime hour, (b) Turner stability factor, (c) $\cos \theta,(\theta$ the zenith angle) at eight stations. Note: Turner stability factor ( 1 : extremely unstable; 2 : moderately unstable; 3 : slightly unstable; 4 : neutral; 5 : slightly stable; 6 : moderately stable; 7: extremely stable) (Appendix).

high turbidity at the eastern side. This phenomenon may be related to the synoptic situation such as a high pressure system off northwestern Taiwan and the Pacific high being at the eastern side of Taiwan.

The atmospheric turbidity increases with relative humidity (Uboegbulam and Davies, 1983), because 

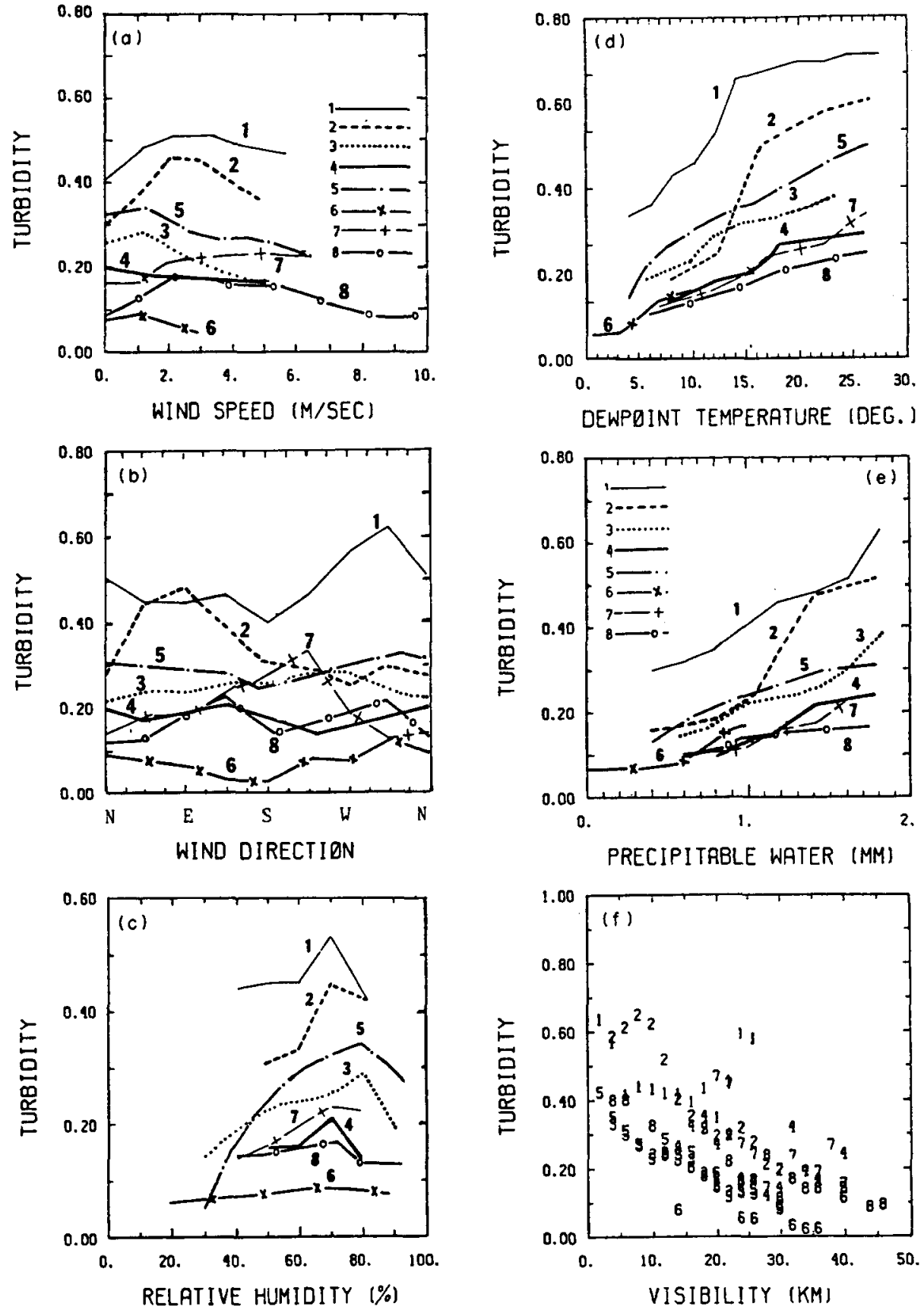

Fig. 5. The variation of mean turbidity averaged at different (a) surface wind speed, (b) wind direction, (c) relative humidity, (d) dewpoint temperature, (e) precipitable water and (f) visibility at eight stations.

hygroscopic aerosol particles grow in size with the increase in relative humidity (Hänel, 1976; Shettle and Fenn, 1979). Such a phenomenon has been noted by Peterson et al. (1981) in central North Carolina in almost every season. In Taiwan the turbidity at most stations also shows such correlations with r.h. $(\leqslant 80 \%$ ) (Fig. 5c). Dependence of turbidity upon dew point temperature (or the precipitable water column according to Equation (11) (Figs 5d and 5e) is also obvious, i.e. the increase of the surface dew point temperature (or the precipitable water) is accompanied with the increase of turbidity. Peterson et al. (1981) have suggested that such a phenomenon is associated with the synoptic weather pattern, since different origins of air mass will bring in different amounts of water vapor in the vertical column.

Horizontal visibility is another meteorological parameter which may be related to turbidity. In a clear hour with low cloudiness, the degradation of visibility must result from the enhancement of low level aero- 
sols. Hence, an inverse correlation between the turbidity and the visibility can be clearly identified in Fig. 5f, i.e. the increase of turbidity is associated with the degradation of visibility $(v)$. Uboegbulam and Davies (1983) have suggested that $\tau_{\mathrm{a}} \propto v^{-1}$. In Fig. 5f, such a relationship can be identified most clearly at station 3 .

\section{Seasonal variation}

Figure 6a plots the seasonal variation of turbidity, which shows that at urban sites (stations 1,2 and 5) high levels of turbidity occur in spring (March, April and May) and fall (September, October and November), with the springtime peak much higher than that of the fall season peak. Low levels of turbidity occur in summer and winter. Suburban (station 7), rural (station 4 and 8) and high mountain (station 6) sites clearly show the springtime peak. Taichung (station 3) has a seasonal variation in phase with Chiayi.

The annual cycle of turbidity observed in Taiwan is completely different from that observed in the temperate zone where the turbidity has winter minimum and summer maximum, e.g. in eastern Canada (Uboegbulam and Davies, 1983), Toronto (Yamashita, 1974), Japan (Yamamoto et al., 1968), Argentina (Carrilho and Berri, 1978), Norway (Hansen, 1974), the U.S. (Flowers et al., 1969; Peterson et al., 1981), etc. The most reasonable cause for such differences must be related to the seasonal variation of the synoptic weather pattern occurring around Taiwan.

Taiwan, being situated in the subtropical region where the Tropic of Cancer passes through, is located at the south-eastern corner of Asia and at the convergence of the continental air mass and the Pacific high pressure system. In winter the cold air mass coming from Mainland China pushes the warm Pacific high southward. Hence, a northeasterly monsoon prevails in Taiwan, and local aerosols are diluted efficiently. During spring the cold air mass interfaces with the warm air mass near Taiwan; therefore there are long periods of rainfall and frequent stagnant air flow which contributes to the accumulation of aerosols in the PBL. During summer, the southwesterly monsoon prevails and the Pacific high dominates the weather pattern. Hence, strong thunderstorms occur frequently in the afternoon and many typhoons pass by. Strong surface wind and thermal activity help to dilute local aerosols. In fall, the Pacific high starts to retreat southward which favors the formation of the stagnant air conditions. However, this period is short as the continental cold air mass advances quickly southward.

The observed high turbidity during spring may also be attributed to the origin of the continental air mass,
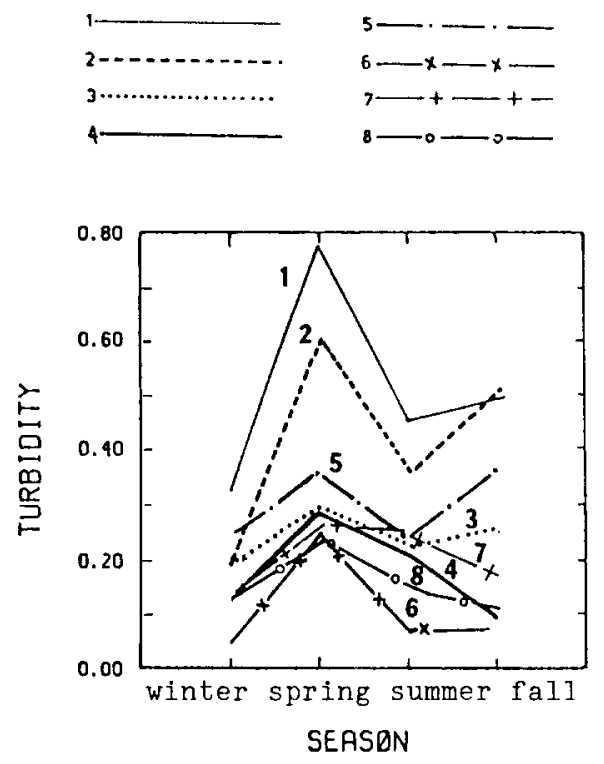

Fig. 6. The seasonal variation of the turbidity at eight stations.

Table 3. The daily mean turbidity during 21-26 April 1985. The standard deviation is in parentheses

\begin{tabular}{lcccccc}
\hline & \multicolumn{7}{c}{ Date (April 1985) } \\
\cline { 2 - 7 } No. & 21 & 22 & 23 & 24 & 25 & 26 \\
\hline 1 & 0.23 & 0.63 & -- & 0.73 & 0.79 & 0.56 \\
& $(0.01)$ & $(0.32)$ & & $(0.41)$ & $(0.38)$ & $(0.01)$ \\
2 & - & 0.74 & 0.88 & 0.80 & 0.93 & 0.92 \\
& & $(0.20)$ & $(0.33)$ & $(0.41)$ & $(0.31)$ & $(0.21)$ \\
3 & - & 0.04 & 0.23 & 0.30 & 0.11 & 0.28 \\
& & $(0.01)$ & $(0.01)$ & $(0.07)$ & $(0.01)$ & $(0.02)$ \\
4 & - & - & 0.41 & 0.37 & 0.27 & 0.32 \\
& & & $(0.08)$ & $(0.05)$ & $(0.04)$ & $(0.03)$ \\
5 & - & 0.14 & 0.49 & 0.35 & - & 0.41 \\
& & $(0.02)$ & $(0.01)$ & $(0.03)$ & & $(0.01)$ \\
6 & - & - & - & 0.02 & - & - \\
& & & 0.47 & $(0.01)$ & & \\
7 & - & - & 0.37 & - & \\
& & & $(0.16)$ & $(0.01)$ & & \\
8 & - & - & 0.40 & 0.31 & 0.25 & 0.32 \\
& & & $(0.16)$ & $(0.04)$ & $(0.02)$ & $(0.01)$ \\
\hline
\end{tabular}



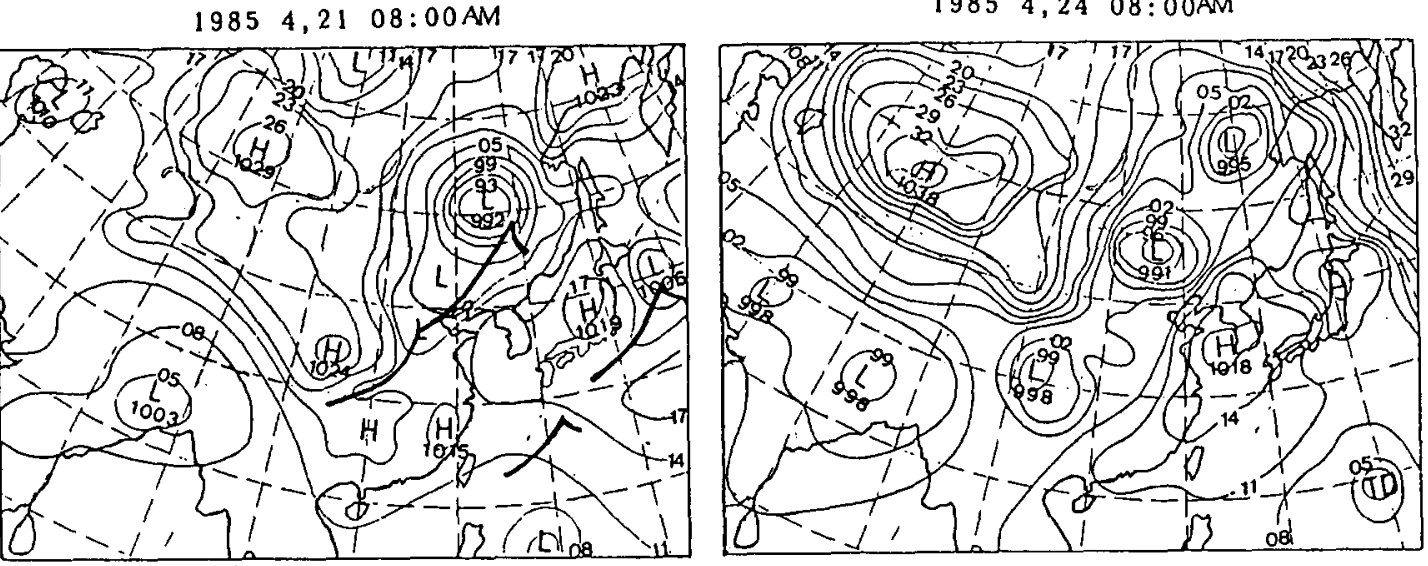

$19854,2208: 00 \mathrm{AM}$

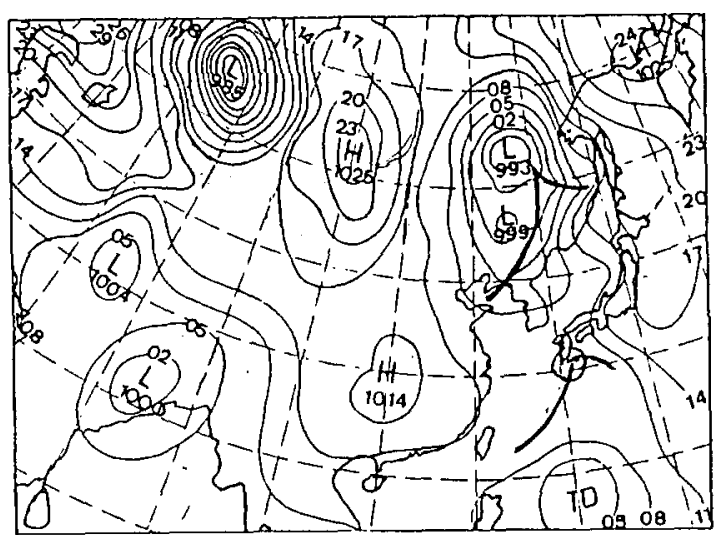

$1985 \quad 4,23 \quad 08: 00 \mathrm{AM}$

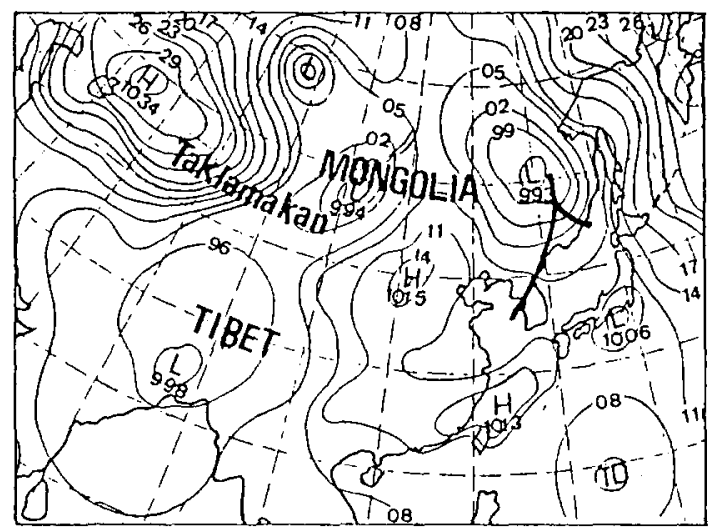

$1985 \quad 4,25 \quad 08: 00 \mathrm{AM}$

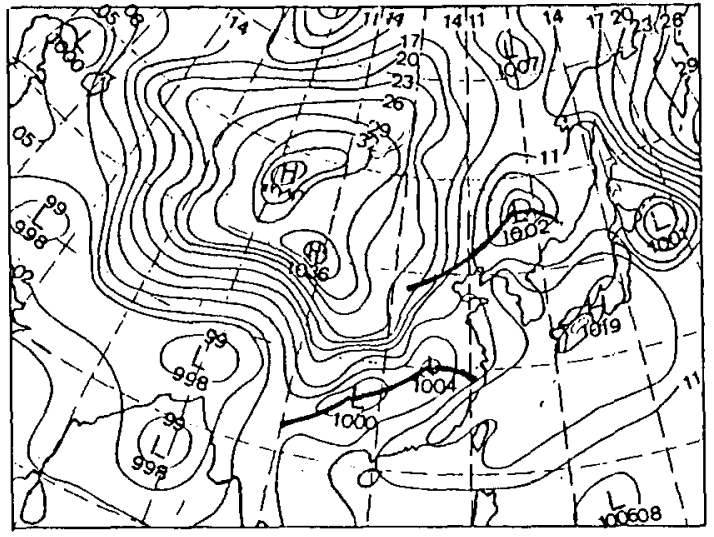

$1985 \quad 4,26 \quad 08: 00 \mathrm{AM}$

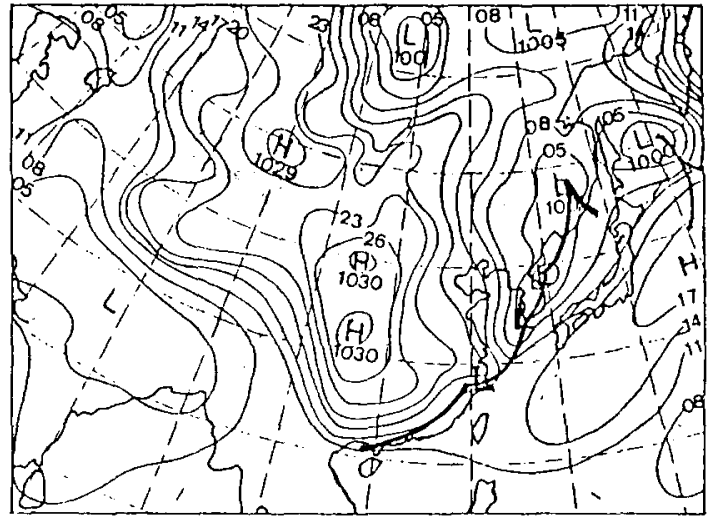

Fig. 7. The surface synoptic weather pattern at 8 a.m. on April (a) 21, (b) 22, (c) 23, (d) 24, (e) 25 and (f) $26,1985$.

which is in contrast to the clean air carried by the Pacific high pressure system.

In order to understand the synoptic conditions in spring, a high turbidity period (21-26 April 1985) was selected for study. During this period, most stations observed above-average daily mean turbidity (Table 3). The surface weather plots (Fig. $7 \mathrm{a}-7 \mathrm{f}$ ) at $8 \mathrm{a} . \mathrm{m}$. every day show that a separate anticyclone centered over the Tibetan Plateau was moving southeastward toward Taiwan, and pushed the tropical depression located over the eastern Philippines slowly to the northeast. Near Taiwan the stationary front on 21 April was gradually replaced by a stagnant high pressure system which stayed till 26 April, when a 

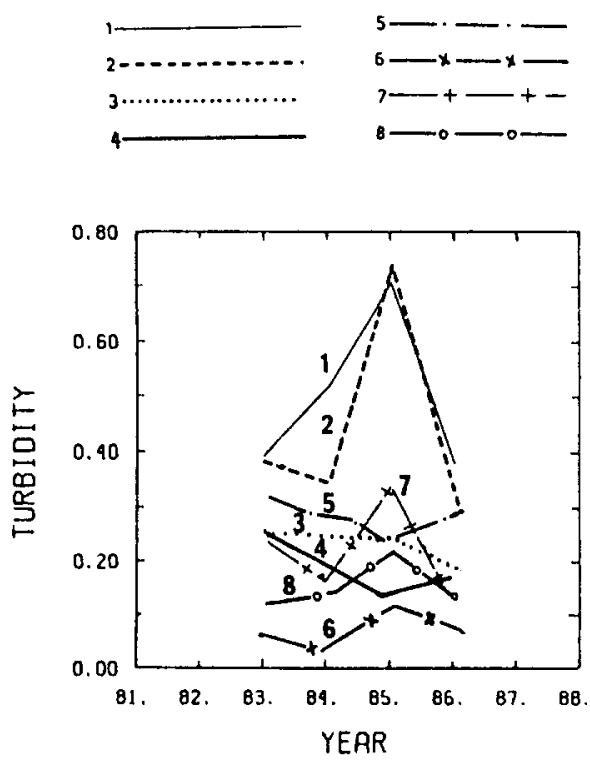

Fig. 8. The interannual variation of turbidity at eight stations.

frontal system extending southwestward from northeastern China approached Taiwan. The synoptic pattern which occurred during this high turbidity period is a typical weather pattern appearing every spring, except that in this case the continental high over Taiwan moved much further southward than usual. It may be significant that the separate anticyclone originated from the Mongolia high was close to Taklamakan where duststorms occur frequently in spring.

\section{CONCLUSION}

The atmospheric turbidity over Taiwan was derived from the measurement data of the direct solar irradiance during the period from July 1982 to June 1987. The mean turbidity over urban sites ranges from 0.30 to 0.48 , which is higher than those over suburban $(0.21-0.23)$, rural $(0.16-0.18)$, and high mountain $(0.09)$ sites (Fig. 1). Such a clear contrast among the urban, suburban, rural and remote sites is also reported in England (Unsworth and Monteith, 1972), U.S. (Flowers et al., 1969) and Toronto (Yamashita, 1974), etc. This fact suggests that the localized aerosol emission and accumulation processes contribute significantly to the aerosol loading. Therefore, a positive correlation exists between atmospheric turbidity and the localized falling dust in Taipei (Fig. 3) where the highest mean turbidity of 0.48 is obtained. Also, a negative correlation is noted between the turbidity and the visibility at all sites (Fig. 5f. The mean turbidity at urban stations are in the $0.25-0.55$ range of British urban sites; whereas those at suburban and rural stations are in the 0.1-0.4 range of British rural sites (Unsworth and Monteith, 1972).

Meanwhile, the diurnal variation of the turbidity shows an increasing trend from morning till noontime or even till late afternoon (Fig. 4a), which is also pointed out by Peterson et al. (1981), Al-Jamal et al. (1987), Yamashita (1974), Unsworth and Monteith (1972), etc. Our analyses indicate that the turbidity increases with the destabilization of the boundary layer (Fig. 4b), and hence with the intensification of solar radiation (or the solar zenith angle), which suggests the importance of the local photochemical processes in generating particulate aerosols.

Low wind speeds $\left(<2 \mathrm{~m} \mathrm{~s}^{-1}\right)$, specific local wind directions, suitable r.h. $(60-80 \%)$ and high column precipitable water (or high dew-point temperatures) were found to enhance the atmospheric turbidity (Fig. $5 \mathrm{a}-\mathrm{e}$ ), as revealed by Uboegbulam and Davies (1983), Peterson et al. (1981), etc. This findings suggest that, besides the local activities in generating aerosols, the meteorological environment is vital to the accumulation and the physical change of aerosols.

The meteorological influence appears most clearly in the seasonal variation of turbidity, which is characterized with the spring-fall maxima and wintersummer minima (Fig. 6) and is different from the cycle of winter-minimum and summer-maximum observed in the temperate zone (Uboegbulam and Davies, 1983; Flowers et al., 1969; Peterson et al., 1981; etc.). In short, frequent stagnant airflow occurring in spring and fall favors the occurrence of high turbidity, while the strong northeasterly monsoon in winter or southwesterly monsoon in summer dilutes aerosols efficiently.

The interannual variation of the turbidity from 1983 to 1986 (Fig. 8) does not provide a meaningful pattern of long-term trends. The maximum turbidity at most stations in 1985 may be due to more active local generation of aerosols, or more frequent stagnant airflow systems, or more efficient long-term transport of aerosols originated for instance from Taklamakan duststorms.

Acknowledgement-The authors want to express gratitude to the Central Weather Bureau for providing the radiation and meteorological data. This research is supported by the National Science Council of the Republic of China under the research grants NSC77-0202-M002-06 and NSC78-0202M002-05. The authors also like to thank Dr D. J. Moore and two anonymous reviewers for providing constructive suggestions.

\section{REFERENCES}

Al-Jamal K., Ayyash S., Rasas M., Al-Aruri S. and Shaban N. (1987) Atmospheric turbidity in Kuwait. Atmospheric Environment 21, 1855-1859.

Ångström A. (1964) The parameters of atmospheric turbidity. Tellus 16, 64-75.

Carrilho M. V. and Berri G. J. (1978) Comportamiento de la turbiedad atmosferica en Buenos Aires y su dependencia con la direccion de viento y tipa de masa da aire. Meteorologica 8/9, 541-549.

Cess R. D., Potter G. L., Ghan S. J. and Gates W. L. (1985) The climatic effects of large injections of atmospheric smoke and dust: a study of climate feedback mechanism 
with one-and three-dimensional climate models. J. geophys. Res. 90, 12,937-12,950.

Coakley Jr. J. A. and Cess R. D. (1983) The effect of tropospheric aerosols on the earth's radiation budget: a parameterization for climate models. $J$. atmos. Sci. $\mathbf{4 0}$, 116-138.

Coakley Jr. J. A. and Cess R. D. (1985) Response of the NCAR community climate model to the radiative forcing by the naturally occurring tropospheric aerosol. J. atmos. Sci. 42, 1677-1692.

Flowers E. C., McCormick R. A. and Kurfis K. R. (1969) Atmospheric turbidity over the United States, 1961-1966. J. appl. Met. 8, 955-962.

Fröehlich C. (1987) Variability of the solar "constant" on time scales of minutes to years. J. geophys. Res. 92, 796-800.

Fröehlich C. and Shaw G. E. (1980) New determination of Rayleigh scattering in the terrestrial atmosphere. Appl. Opt. 19, 1773-1775.

Galindo I. (1986) Anthropogenic aerosols and their regional scale climatic effects. In Aerosols and Their Climatic Effects (edited by H. E. Gerber and A. Deepak), pp. 245-259.

Hänel G. (1976) The properties of aerosol particles as functions of the relative humidity at thermodynamic equilibrium with the surrounding moist air. Adv. Geophys. 19, $73-188$.

Hänel G. (1987) Radiation budget of the boundary layer. Part III: The mean solar volume absorption coefficients of water vapor for direct and diffuse radiation. Beitr. Phys. Atmosph. 60, 248-252.

Hansen V. (1974) Determination of atmospheric turbidity parameters from spectral solar radiation measurements. Arch. Meteor, Geophys. Bioklim, B22, 301-308.

Lacis A. A. and Hansen J. E. (1974) A parameterization for the absorption of solar radiation in the earth's atmosphere. J. atmos. Sci. 31, 118-133.

List R. J. (1971) Smithsonian Meteorological Tables, 6th Edition. Smithsonian Institution Press.

Liou K. N. (1980) An Introduction to Atmospheric Radiation. Academic Press, New York.

Paltridge S. W. and Platt C. M. R. (1976) Radiative Processes in Meteorology and Climatology. Elsevier, Amsterdam.

Peterson J. T., Flowers E. C., Berri G. T., Reynolds C. L. and Rudisill J. H. (1981) Atmospheric turbidity over central North Carolina. J. appl. Met. 20, 229-241.

Potter G. L. and Cess R. D. (1984) Background tropospheric aerosols: Incorporation within a statistical-dynamical climate model. J. geophys. Res. 89, 9521-9526.

Reck R. A. and Hummel J. R. (1981) Influence of aerosol optical properties on surface temperatures computed with a radiative-convective model. Atmospheric Environment $15,1727-1731$
Ramanathan V. (1988) The greenhouse theory of climate change: a test by an inadvertent global experiment. Nature 240, 203-299.

Shettle E. P. and Fenn R. W. (1979) Models for the aerosols of the lower atmosphere and the effects of humidity variations on their optical properties. AFGL-TR-79-0214, Environ. Res. Pap. No. 676, Air Force Geophysics Laboratory.

Tomasi C. (1977) Precipitable water vapor in atmosphere characterized by temperature inversions. J. appl. Met. 16, 237-243.

Turner D. B. (1961) Relationships between 24-h mean air quality measurements and meteorological factors in Nashville, Tennessee. J. Air Pollut. Control Ass. 11, 483-489.

Uboegbulam T. C. and Davies J. A. (1983) Turbidity in eastern Canada. J. clim. appl. Met. 22, 1384-1392.

Unsworth M. H. and Monteith J. L. (1972) Aerosol and solar radiation in Britain. Q. Jl R. met. Soc. 98, 778-797.

Wang W.-C., Wuebbles D. J., Washington W. M., Isaacs R. G. and Molnar G. (1986) Trace gases and other potential perturbations to global climate. J. geophys. Res. 24, $110-140$.

Yamamoto G., Tanaka M. and Arao K. (1968) Hemispherical distribution of turbidity coefficient as estimated from direct solar radiation measurements. J. Met, Soc. Japan 46, 278-300.

Yamashita S. (1974) A comparative study of turbidity in an urban and a rural environment at Toronto. Atmospheric Environment 8, 507-518.

\section{APPENDIX: THE TURNER STABILITY FACTOR}

The Turner stability factor was proposed by Turner (1961) to distinguish the degree of stability of the airflow in the boundary layer near surface, based on the surface meteorological observation. Seven different kinds of stability factor are: (1) extremely unstable, (2) moderately unstable, (3) slightly unstable, (4) neutral, (5) slightly stable, (6) moderately stable and (7) extremely stable. They are determined based on the following two tables.

Table A1. Classification of sunshine intensity

\begin{tabular}{lll}
\hline $\begin{array}{l}\text { Solar zenith } \\
\text { angle }\end{array}$ & \multicolumn{2}{c}{ Cloud cover } \\
\hline$<15^{\circ}$ & Weak & Weak \\
$15^{\circ}-30^{\circ}$ & Weak & Moderate \\
$30^{\circ}-60^{\circ}$ & Moderate & Medium \\
$60^{\circ}-90^{\circ}$ & Medium & Strong \\
\hline
\end{tabular}

Table A2. Classification of Turner stability factor

\begin{tabular}{|c|c|c|c|c|c|c|c|}
\hline \multirow{2}{*}{$\begin{array}{l}\text { Wind speed } \\
\text { (kts) }\end{array}$} & \multirow[b]{2}{*}{ Strong } & \multicolumn{2}{|c|}{$\begin{array}{c}\text { Daytime } \\
\text { sunshine intensity }\end{array}$} & \multirow[b]{2}{*}{ Weak } & \multirow{2}{*}{$\begin{array}{c}100 \% \\
\text { Cloud cover }\end{array}$} & \multicolumn{2}{|c|}{$\begin{array}{l}\text { Night-time } \\
\text { cloud cover }\end{array}$} \\
\hline & & Medium & Moderate & & & $>50 \%$ & $<50 \%$ \\
\hline$<1$ & 1 & 1 & 2 & 3 & 4 & 6 & 7 \\
\hline 2 & 1 & 2 & 2 & 3 & 4 & 6 & 7 \\
\hline 3 & 1 & 2 & 2 & 3 & 4 & 6 & 7 \\
\hline 4 & 1 & 2 & 3 & 4 & 4 & 5 & 6 \\
\hline 5 & 1 & 2 & 3 & 4 & 4 & 5 & 6 \\
\hline 6 & 2 & 2 & 3 & 4 & 4 & 5 & 6 \\
\hline 7 & 2 & 2 & 3 & 4 & 4 & 4 & 5 \\
\hline 8 & 2 & 3 & 3 & 4 & 4 & 4 & 5 \\
\hline 9 & 2 & 3 & 3 & 4 & 4 & 4 & 5 \\
\hline 10 & 3 & 3 & 4 & 4 & 4 & 4 & 5 \\
\hline 11 & 3 & 3 & 4 & 4 & 4 & 4 & 4 \\
\hline$>12$ & 3 & 4 & 4 & 4 & 4 & 4 & 4 \\
\hline
\end{tabular}

